\title{
Trauma, Its Criteria, and Its Aftermath
}

\author{
By Jack M. Gorman, MD
}

A major impetus for posttraumatic stress disorder (PTSD) research in the United States has come from the Department of Veterans Affairs (VA). Faced at first with thousands of Vietnam War veterans asking for disability and healthcare benefits decades after the war's end, then with returnees from the first Gulf War, and now the Iraq War veterans making similar claims, it became clear to the VA that understanding exactly what kinds of war trauma produce PTSD and how to treat it would be an essential undertaking. The venture may not sound entirely altruistic; a lifetime of benefits from the VA on the basis of having sustained PTSD during combat is expensive to the government. Therefore, the VA clearly needs to know how to recognize legitimate cases. But doing so is far from simple.

The Diagnostic and Statistical Manual of Mental Disorders, Fourth Edition-Text Revision definition of a qualifying traumatic event capable of inducing PTSD demands either being personally in or witnessing a life-threatening event with real potential for death or physical harm. Merely being afraid, being criticized or humiliated by a superior officer, or missing home would not seem sufficient to cause PTSD. How close, however, must a soldier or sailor actually be to a life-threatening combat situation to be affected? Some insist that only those actually under fire who sustained serious injuries or witnessed the death or dismemberment of comrades are exposed to sufficiently severe psychological trauma to get PTSD.

Others feel that less immediate exposures are sufficiently psychologically damaging, however. Take, for example, a 35-year-old married accountant with two children who is a member of the army reserve. For several years, he has lived in blissful denial of the possibility that someday he might be called upon to actually face an armed enemy. Now, unfortunately, he is called to duty and sent to a military supply post in Iraq. He does not actually come under fire; indeed, during his entire tour of duty he never fires his weapon, but for 2 years he is constantly "on call" for having to do so. Several of his friends from his old reserve unit are engaged in patrols and one of them is killed during a roadside attack by insurgents. $\mathrm{He}$ is not present when this happens, but the death of his friend haunts him and, in addition to mourning the death, he begins to wonder at what point he might face a similar fate. One month after the incident that takes his comrade's life, he has nightmares in which he is confronted by a seemingly innocent young Iraqi male who is in fact a suicide bomber; he is killed in the ensuing attack. These nightmares wake him in a cold sweat without fail. During the day, due to lack of sleep, he is constantly fatigued and anxious. Phones ringing in the office startle him and he is never at peace. He develops chest pain and is evaluated medically, but his symptoms turn out to lack any cardiac basis and he is returned to active duty. Several other "psychosomatic" complaints come and go. In general, it is a thoroughly miserable experience. Unfortunately, the symptoms do not entirely relent when his tour of duty is over and he returns home. Although his former job is still open, changes have occurred in his office, his work is no longer as desirable, and he has missed opportunities for promotion. He still has nightmares of suicide bombers occur-

Dr. Gorman is the editor of this journal and adjunct professor of psychiatry at Mount Sinai School of Medicine in New York City. 
ring once or twice a week. His wife and children notice that he seems distracted and unable to relate to them with his former emotional intensity. He is generally depressed and anxious. Finally, he is finally persuaded to see a psychiatrist, who makes a diagnosis of PTSD. A claim is made to the VA for disability benefits.

There is no question that this hypothetical former soldier meets many of the symptomatic criteria for PTSD. Perhaps the worst aspect of the case is that he receives little social approbation for his efforts or his suffering. Unlike veterans of the first GulfWar, generally seen by the American public as a justified and successful campaign, many Americans now doubt the wisdom of our current efforts in Iraq. Returning troops often feel like those who returned from Vietnam; heroes' welcomes are generally not forthcoming. Lack of social support is a risk factor for PTSD, further strengthening the case that this soldier is indeed psychiatrically afflicted.

And yet, of course, he was never himself "in harm's way"; he was never fired upon or fired at anyone else. Does this case then qualify for a diagnosis of PTSD? To complicate matters further, our soldier-accountant suffers a heart attack at 55 years of age and insists that it was spurred on by his original traumatic experience in Iraq.
What is the evidence that exposure to a psychologically traumatic event can set in motion cardiovascular changes that ultimately lead to a myocardial infarction that, in the absence of such trauma, would not have occurred? How does one balance all the usual risk factors (ie, obesity, high cholesterol, lack of exercise, etc.) with a psychologically damaging event?

These are not easy questions. However, the VA clearly needs to call upon the best available science and expertise to sort out the answers. Political questions aside, it is generally agreed that PTSD and other trauma-related medical conditions related to combat activity are the responsibility of the VA's extensive benefit and healthcare network. On the other hand, some attempt at case definition is necessary.

The articles in this month's CNS Spectrums, guest edited by Ehud Klein, MD, of the Rambam Medical Center in Haifa, Israel, offer some guidance in this regard. Indeed, the Israeli experience with the psychological consequences of combat-related trauma will undoubtedly be useful. Nevertheless, there are important differences between the Israeli and American experiencesparticularly with respect to society's response to combat veterans - that will make it incumbent upon the VA to seek its own path. CNS

\section{Now Available Online at www.cnsspectrums.com}

\section{CME-ACCREDITED MONOGRAPH SUPPLEMENT New Approaches in Managing Chronic Insomnia} An expert review of clinical challenges in psychiatry

by David N. Neubauer, MD 


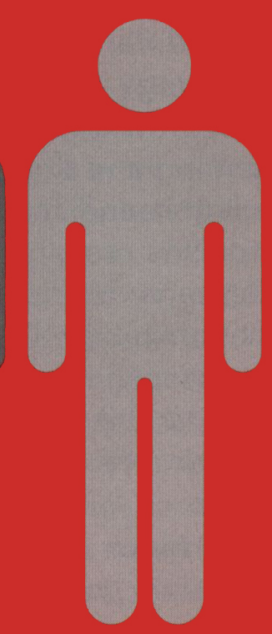

\title{
$13 \%$ of patients had diabetes in the landmark CATIE schizophrenia study at baseline -4 times more common than in the general population.'
}

\author{
Be aware. \\ Screen and monitor your patients. \\ Make a difference.
}

Reference: 1. Golf DC, Sullivan LM, McEvoy JP, et al. A comparison of ten-year cardiac risk estimates in schizophrenia patients from the CATIE study and matched controls. Schizophr Res. 2005;80:45-53. 